\title{
Desenvolvimento e caracterização de \\ esferas de quitosana/ Dysphania ambrosioides (L.) Mosyakin \& Clemants
}

\section{Production and characterization of chitosan spheres/ Dysphania ambrosioides (L.) Mosyakin \& Clemants}

\author{
Mylena de Araújo Régis ${ }^{1}$, Rosana Araújo Rosendo ${ }^{2}$, \\ Luanna Abílio Diniz Melquiades de Medeiros ${ }^{2}$, Marcus Vinícius Lia Fook ${ }^{3}$, \\ Rossemberg Cardoso Barbosa ${ }^{3}$, Ana Beatriz Maximo Figueiredo ${ }^{2}$, Walter Gleybson Antas de Moraes ${ }^{1}$, \\ Rafael Rodrigues de Siqueira ${ }^{1,}$ Arthur Willian de Lima Brasil ${ }^{1}$
}

\footnotetext{
${ }^{1}$ Universidade Federal de Campina Grande (UFCG), Campus de Patos, Rua Pedro Firmino, S/N Bairro Salgadinho; CEP: 58.700-350, Patos, PB, Brasil.

${ }^{2}$ Universidade Federal de Campina Grande (UFCG), Campus de Patos, Rua João Soares, nº 127 Bairro Brasília; CEP: 58.700-318, Patos, PB, Brasil.

${ }^{3}$ Universidade Federal de Campina Grande (UFCG), Laboratório de avaliacão e desenvolvimento de Biomateriais do Nordeste (CERTBIO), Rua Aprígio Veloso, 882, Bairro Bodoncongó; CEP. 58429-900, Campina Grande, PB, Brasil.

e-mail: mylenaregis@outlook.com, cesprodonto@hotmail.com, luannaabiliod@gmail.com, viniciusliafook@gmail.com, rcbvet@gmail.com, anabiamf22@yahoo.com, walter_morais18@hotmail.com, rrodriguesdesiqueira@mail.rooseelt.edu, arthurwillian7@yahoo.com.br
}

\begin{abstract}
RESUMO
O objetivo do presente trabalho foi produzir e caracterizar um biomaterial na forma de esferas de quitosana/ Dysphania ambrosioides (L.) Mosyakin \& Clemants (mastruz) a fim de associar características positivas de ambos materiais, a quitosana com potencial osteoindutor e o mastruz capacidade de regeneração óssea, formando biomaterial a ser utilizado na formação e regeneração óssea. A planta foi coletada, identificada botanicamente e obtido extrato alcoólico bruto de Dysphania ambrosioides (L.) Mosyakin \& Clemants (EAB). Para produção das esferas de quitosana e quitosana com EAB utilizou-se a técnica de Gelificação Ionotrópica. As esferas foram divididas em três grupos: um grupo de quitosana pura, outro com concentração menor de $\mathrm{EAB}$ e o terceiro com a maior concentração de EAB. Estas foram caracterizadas por Microscopia Óptica (MO), Microscopia Eletrônica de Varredura (MEV) e análise do Grau de Intumescimento (GI). A MO evidenciou nas superfícies externa e interna, esferas com limites definidos e com mudança de cor à medida que o percentual do EAB foi aumentado, tornando-se mais escuras. A MEV revelou, em esferas de maior concentração, quando comparado as de menor concentração: uma diminuição no tamanho e aumento da quantidade e da intercomunicação dos poros, além da alteração do formato geométrico tanto das esferas quanto dos seus poros. Na análise do Grau de intumescimento não houve diferenças significativas entre os grupos. Conclui-se que foi possível a produção de esferas de quitosana e quitosana/ Dysphania ambrosioides (L.) Mosyakin \& Clemants (mastruz), que no grupo com maior percentual de EAB as amostras apresentaram-se mais escuras e com maior quantidade e intercomunicação dos poros e que embora tenha havido o intumescimento, não foi observada diferença significativa entre os grupos.
\end{abstract}

Palavras-chave: Quitosana. Plantas medicinais. Regeneração óssea.

\section{ABSTRACT}

The objective was to produce and characterize a biomaterial in the form of chitosan spheres/ Dysphania ambrosioides (L.) Mosyakin \& Clemants (mastruz) in order to associate positive characteristics of both mate- 
rials, chitosan with osteoinductive potential and the bone regeneration ability of mastruz, producing a biomaterial to use as bone former and regenarator. Plant specimens were collected, identified botanically and crude alcohol extract (CAE) were obtained. For the production of the chitosan and chitosan spheres with $\mathrm{CAE}$, the Ionotrope Gellification technique was used. The spheres were divided into three groups: one example group of pure chitosan; a second example group with low CAE concentration and a third example group with a higher CAE concentration; and them characterized by Optical Microscopy (OM), Scanning Electron Microscopy (SEM) and swelling degree (SD). OM showed on the external and internal surfaces, spheres with defined limits and with color changed as the percentage of CAE was increased, becoming darker. The SEM showed, in spheres with higher CAE concentration, in comparison with the ones with low CAE concentration: A decrease in size, increase in the quantity and intercommunication of the pores, and the alteration of the geometric shape of both the spheres and their pores. In the analysis of the swelling degree, there were no significant differences between the groups. It is possible to produce chitosan spheres / Dysphania ambrosioides (L.) Mosyakin \& Clemants (mastruz) which in the group with the highest percentage of CAE the samples were darker and with higher amounts and intercommunication pores and that although there was swelling, no significant difference was observed between the groups.

Keywords: Chitosan. Medical Plants. Bone Regeneration.

\section{INTRODUÇÃO}

Biomateriais são definidos como dispositivos que entram em contato com sistemas biológicos (incluindo fluidos biológicos), dentre eles dispositivos biomédicos, materiais implantáveis, dispositivos para liberação de medicamentos, órgãos artificiais, dentre muitos outros. Estes atuam em aplicações diagnósticas, vacinais, cirúrgicas ou terapêuticas, podendo ser constituídos de origem sintética ou natural, sendo a utilização dos mesmos na área da saúde cada vez mais comum, com intenso crescimento observado no mercado [1].

Defeitos com perda de massa óssea frequentemente são reparados com enxertos ósseos autógenos. No entanto, eles apresentam algumas desvantagens, como morbidade da área doadora, reabsorção pósoperatória, contornos irregulares dos enxertos angulares e complicações como dor crônica e lesões vasculares durante o procedimento cirúrgico [2]. Diante disto, têm se buscado biomateriais hábeis para promover esta substituição, evitando o uso de enxertos ou transplantes ósseos [3]. Esses biomateriais podem ser de fácil dissolução e absorção, ao mesmo tempo em que permitem e estimulam a formação óssea [4, 5, 6].

Nesse âmbito, a quitosana, um polissacarídeo proveniente da desacetilação da quitina, obtida essencialmente da carapaça de caranguejo e camarão apresenta-se como uma possibilidade. Sendo considerada uma macromolécula não tóxica, biocompatível e com comprovadas propriedades anti-inflamatória e cicatrizante [7], o interesse por este biopolímero tem aumentado, ainda mais pela maior capacidade cicatrizante na quitosana quando comparado à quitina, visto que quanto maior o grau de desacetilação, maior a resistência das feridas à ruptura e mais fibroblastos ativos aparecem no local [8]. Nos últimos anos, a quitosana tem sido vastamente utilizada na veiculação de medicamentos, bem como na engenharia de tecidos aplicada à odontologia [9].

Os fitoterápicos são outras substâncias que tem despertado o interesse da comunidade científica [10], quando utilizados em combinação com biomateriais osteoindutores, podem acelerar o processo de formação do tecido ósseo funcionando como um agente potencializador [11]. O principal intuito na indicação do uso de fitoterápicos não é substituir os medicamentos registrados e já comercializados, mas aumentar as opções terapêuticas dos profissionais de saúde; ofertando medicamentos equivalentes, com menor custo, mecanismos de ação mais adequados e com indicações terapêuticas complementares às medicações já existentes [10].

Dentre as plantas medicinais estudadas, o mastruz (Dysphania ambrosioides (L.) Mosyakin \& Clemants) apresenta propriedades que despertam o interesse na área médica-odontológica; como a capacidade de acelerar o reparo ósseo [12]; Sousa [13] sugeriu que o extrato de mastruz aumentou o efeito antiinflamatório e cicatrizante nos tecidos pulpar e periodontal de dentes reimplantados, diminuindo a intensidade de polimorfonucleares, o abscesso, a necrose e estimulando o reparo ósseo alveolar e osteogênese [12, 14]. Resultados de Penha [12] corroboraram ao mostrar que o uso do extrato de Mastruz é um método altamente promissor para a obtenção de reparo ósseo rápido para uso na prática clínica.

Esta planta produz diversos metabólitos secundários responsáveis por suas atividades farmacológicas, tais como compostos fenólicos, catequinas, esteróides, flavonóides, taninos, triterpenóides e óleo essencial, sendo considerados os princípios ativos responsáveis por suas propriedades terapêuticas [15]. Sendo assim, este trabalho objetivou desenvolver e avaliar esferas de quitosana/ Dysphania ambrosioides (L.) Mosyakin \& Clemants liofilizadas para aplicação como biomaterial, com ênfase na regeneração óssea. 


\section{MATERIAIS E MÉTODOS}

\subsection{Materiais}

Os materiais utilizados foram quitosana de médio peso molecular - com grau de desacetilação em torno de 90\% e grau de cristalinidade de aproximadamente 50\% (CERTBIO); ácido Acético Glacial - Neon (Lote 21352), tripolifosfato de sódio - Sigma Aldrich ${ }^{\circledR}$ (Lote 12421JIV) e solução tampão fosfato-salino(PBS) -

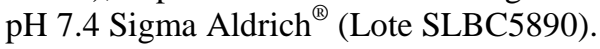

\subsection{Métodos}

2.2.1 Coleta da planta, identificação botânica e obtenção do extrato vegetal

A planta é cultivada e foi coletada no Horto de Plantas Medicinais do Instituto de Pesquisa em Fármacos e Medicamentos (IPeFarmM) da Universidade Federal da Paraíba (UFPB) em João Pessoa- PB (Figura 1A).

No intuito de fazer a identificação botânica da espécie vegetal utilizada no estudo, partes aéreas (caule, folhas e frutos) de plantas adultas frescas foram prensadas, em seguida postas em estufa artesanal, para secagem, por 72 horas, para confecção de exsicatas.

O técnico F.E.M.A realizou a identificação botânica no herbário do Centro de Saúde e Tecnologia Rural (CSTR) da UFCG, localizado na cidade de Patos-PB, onde amostras representativas das exsicatas foram depositadas no Herbário CSTR (Figura 1B).

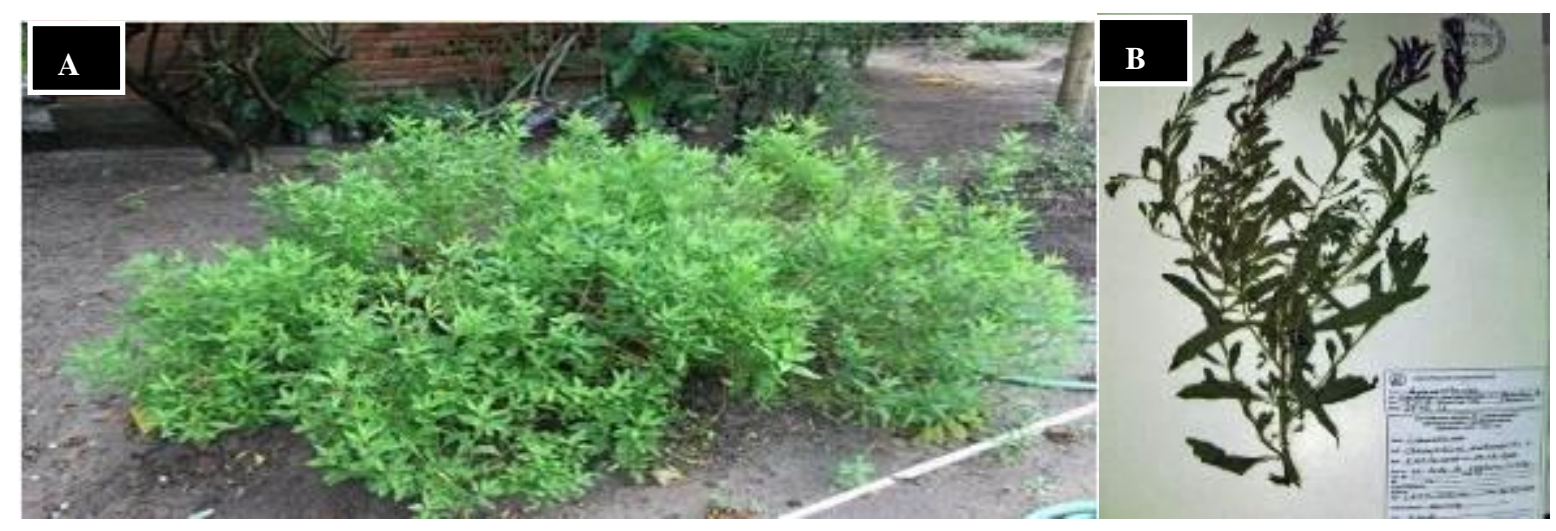

Figura 1: Espécie vegetal no Horto de Plantas Medicinais do IPeFarmM (A); Exsicata depositada no Herbário CSTR (B) (AUTOR, 2017).

Para obtenção do extrato vegetal de Dysphania ambrosioides (L.) Mosyakin \& Clemants (mastruz), a metodologia para produção foi baseada no trabalho de Brasileiro et al. [16]. Ele foi preparado a partir das partes aéreas (caule, folhas e frutos) de plantas adultas frescas. Após coletadas, foram cortadas em pequenos pedaços com auxílio de tesoura e em seguida pesadas, totalizando $4870 \mathrm{~g}$.

A planta cortada foi colocada em um percolador de aço inox a temperatura ambiente $\left(26^{\circ} \mathrm{C}\right)$ com etanol a $95 \%$ e deixada em repouso por 72 horas.

No momento da extração, já era realizada a filtragem, por meio da inserção do algodão na parte inferior do percolador resultando em um líquido de cor verde o qual foi acondicionado em béquer e transferido para balões de fundo redondo. Posteriormente, o filtrado foi colocado em um rota evaporador R-210 BUCHI, à pressão de $64 \mathrm{Bar}$ com temperatura de $50^{\circ} \mathrm{C}$. Ao final dessa etapa, foi obtido $100,7217 \mathrm{~g}$ de um material escuro, pastoso, denominado extrato alcoólico bruto (EAB) (Figura 2A e 2B). 

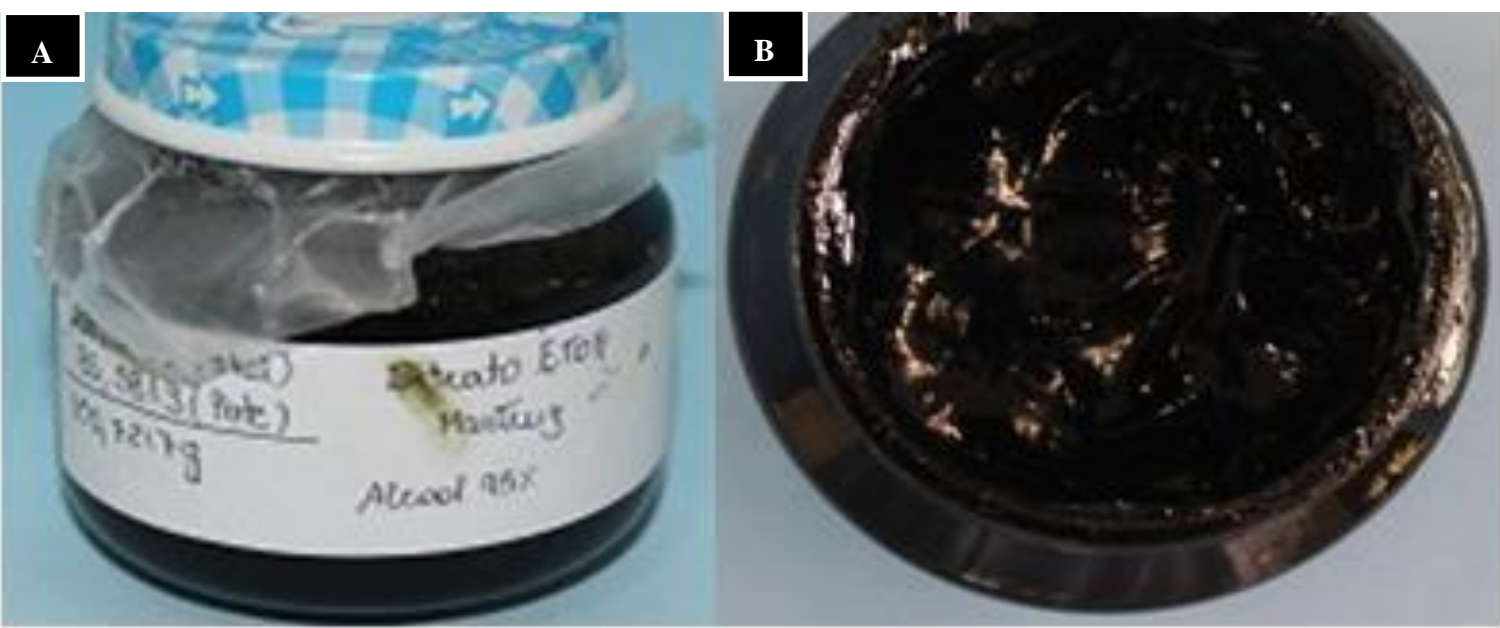

Figura 2: Recipiente contendo o extrato (A) e imagem superior do recipiente contendo o extrato (B) (AUTOR, 2017).

\subsubsection{Preparação das esferas de quitosana e quitosana/ Dysphania ambrosioides (L.) Mosyakin \& Clemants}

Foi preparada uma solução de quitosana $2 \%(\mathrm{~m} / \mathrm{v})$ por meio da dissolução de $30 \mathrm{~g}$ de quitosana em partículas em 1,5 litro de solução de ácido acético glacial $1 \%$ (v/v), no agitador mecânico durante $24 \mathrm{~h}$ a $435 \mathrm{rpm}$. A quitosana utilizada foi de médio peso molecular, com grau de desacetilação em torno de $90 \%$ e grau de cristalinidade de aproximadamente $50 \%$.

Em seguida foram retiradas porç̃oes menores da solução da quitosana às quais foram adicionadas o EAB, resultando $100 \mathrm{~mL}$ de cada solução com $5 \%$ e $20 \%$ de EAB com relação a massa do polímero empregado, e uma porção que não foi adicionado EAB também de $100 \mathrm{~mL}$.

Os passos para dissolução do EAB na solução de quitosana se iniciam na pesagem do EAB em balança analítica, foi feita colocando-o em um Becker e posteriormente adicionando a solução de quitosana, sendo a mistura realizada sob agitação mecânica por 30 minutos a 435 rpm, obtendo- se então soluções de quitosana com $5 \%$ e $20 \%$ de EAB.

Posteriormente às diluições, foi selecionada a técnica de Gelificação Ionotrópica com finalidade de se obter as esferas. Para tanto, foram adicionados separadamente, $10 \mathrm{~mL}$ de cada solução $(0 \%, 5 \%$ e $20 \%$ de EAB) em seringas (Descarpack) equipadas com uma agulha de 25 milímetros de comprimento e 0,80 milímetros de diâmetro (NIPRO). O conjunto (seringa/agulha/solução) foi então acoplado a uma bomba de infusão com velocidade de $20 \mathrm{~mL} / \mathrm{h}$ (Figura 3A). As gotículas formadas foram recolhidas em um béquer contendo $100 \mathrm{~mL}$ de solução de TPP (Tripolifosfato de Sódio) a 5\%, formando as esferas. As mesmas permaneceram na solução de TPP por 30 segundos.

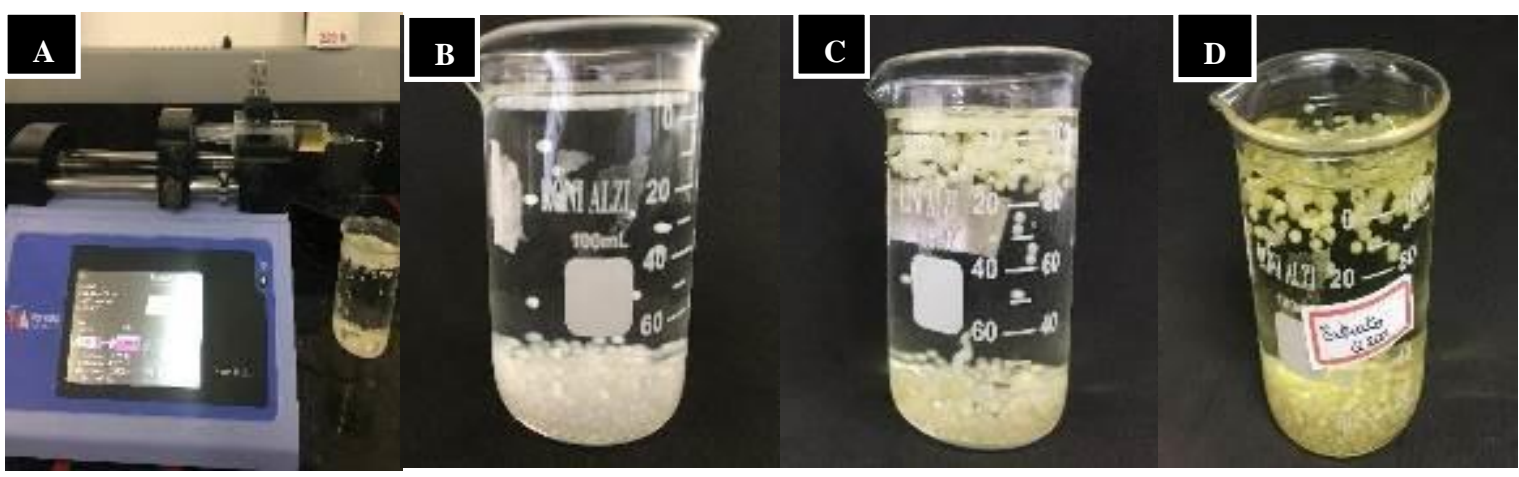

Figura 3: Conjunto (seringa/agulha/solução) acoplado a bomba de infusão e formação das esferas (A), Esferas de quitosana em repouso na solução de TTP 5\% (B), Esferas de quitosana com 5\% de EAB em repouso na solução de TTP 5\%(C), Esferas de quitosana com 20\% de EAB em repouso na solução de TTP 5\% (D) (AUTOR, 2017). 
Decorrido esse tempo, as esferas foram lavadas em $10 \mathrm{~mL}$ de água destilada, permanecendo imersas por cinco minutos, depois foram despejadas em uma peneira. Esse processo de lavagem foi realizado por mais duas vezes, totalizando três ciclos para cada um dos grupos.

Concluído o terceiro ciclo de lavagem, as esferas de quitosana e quitosana/ Dysphania ambrosioides (L.) Mosyakin \& Clemants foram dispostas em discos de papel filtro para remover o excesso de água (Figura 4) As esferas foram inseridas em tubos falcon e levadas ao liofilizador por 72horas. Depois de liofilizadas foram encaminhadas ao ultrafreezer por 24 horas, organizadas em eppendorf e levadas às caracterizações.

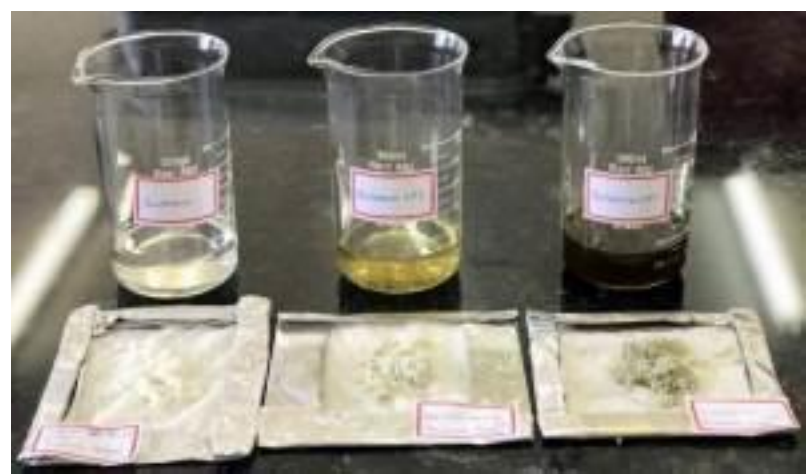

Figura 4: Solução/Esferas de quitosana e soluções/esferas de quitosana com $5 \%$ e $20 \%$ de EAB em papel filtro (AUTOR, 2017).

\subsection{Técnicas de Caracterização}

As esferas de quitosana (Q0) e quitosana com o extrato de Dysphania ambrosioides (L.) Mosyakin \& Clemants em diferentes concentrações (Q5 e Q20), foram caracterizadas pelas técnicas de Microscopia Ótica (MO), Microscopia Eletrônica de Varredura (MEV) e Grau de Intumescimento.

\subsubsection{Microscopia Óptica (MO)}

Para caracterização por microscopia ótica das esferas de quitosana sem e com o extrato Dysphania ambrosioides $($ L. ) Mosyakin \& Clemants em diferentes concentrações, foi utilizado um Microscópio Ótico da marca Hirox, modelo (SHX-13M).

Foram realizadas imagens com o aumento de 40X, 100X e 160X tanto da superfície externa quanto da superfície transversal de corte; estas últimas superfícies foram obtidas a partir do corte das esferas em duas partes, utilizando-se uma lâmina de bisturi $\mathrm{n}^{\circ} 15 \mathrm{C}$.

\subsubsection{Microscopia Eletrônica de Varredura (MEV)}

Para esse ensaio, foram realizadas imagens da superfície externa das esferas com os aumentos de 1000X e 2000X e 5000X, como também da superfície interna transversal de corte com aumentos de 200 e 2000X; estas últimas superfícies foram obtidas a partir do corte das esferas em duas partes utilizando-se uma lâmina de bisturi $\mathrm{n}^{\circ}$ 15C (Solidor), sendo selecionado o equipamento modelo TM-1000 da marca Hitachi, que é utilizado para avaliar amostras poliméricas de até 10.000x e captura de elétrons retroespalhados, não necessitando do recobrimento das amostras.

\subsubsection{Grau de Intumescimento}

Para execução do ensaio, um conjunto de 5 esferas representou uma amostra, onde cada esfera foi então devidamente pesada a seco, depois de liofilizadas, em balança analítica de precisão da BEL ENGINEERING, antes da imersão em solução de PBS (Sigma Aldrich).

Cada amostra foi então imersa em $5 \mathrm{~mL}$ da solução de PBS por um período de 24 horas. Posteriormente, foram removidas da solução, dispostas por 30 segundos em papel absorvente para eliminar o excesso da solução, e o peso úmido de cada amostra foi novamente aferido na mesma balança. O cálculo do grau de intumescimento foi realizado segundo a equação abaixo. Os resultados do intumescimento serão apresentados em porcentagem. 


$$
G I=M f-M o / M o x 100
$$

Onde: GI - Grau de intumescimento

$\mathrm{M}_{\mathrm{f}}$ - Massa final (intumescida)

$$
\mathrm{M}_{0} \text { - Massa seca }
$$

\subsection{Análise dos Dados}

Os resultados das caracterizações no MO e MEV foram avaliados qualitativamente, já os resultados do grau de intumescimento foram tabulados e apresentados de forma quantitativa e submetidos à análise estatística ANOVA com valor $\mathrm{p}<0,05$.

\section{RESULTADOS E DISCUSSÃO}

\subsection{Microscopia óptica (MO)}

\subsubsection{Superfície externa}

A Figura 5 ilustra a superfície externa das esferas utilizando-se um aumento de 40X no MO, na qual se observa que as esferas são bem delimitadas e que se tornaram mais escuras à medida que o percentual do extrato de Dysphania ambrosioides (L.) Mosyakin \& Clemants foi aumentado, evidenciando a incorporação deste.

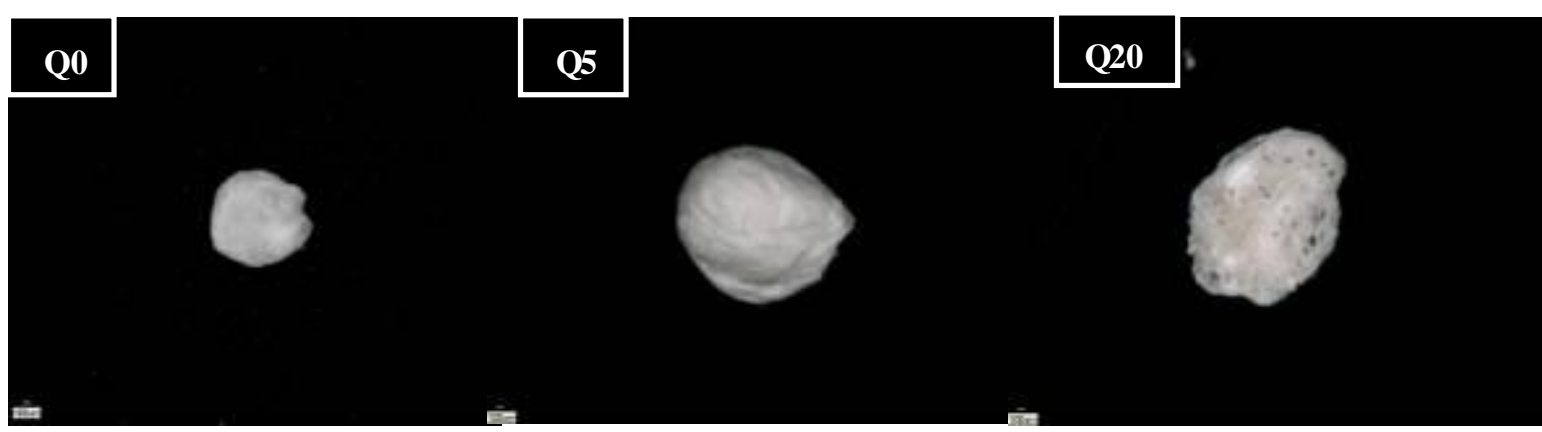

Figura 5: Imagens das esferas no MO com aumento de 40X. (Q0) Esferas de quitosana, (Q5) Esferas quitosana $+5 \%$ EAB e (Q20) Esferas quitosana +20\% EAB (AUTOR, 2017).

As imagens das esferas com o aumento de $100 \mathrm{X}$ e $140 \mathrm{X}$ no MO confirmam o que foi relatado anteriormente com relação à delimitação, e ainda evidencia áreas verde escuras nas esferas pertencentes aos grupos Q5 e Q20, sugestivas do extrato não dissolvido (Figura 6 e 7).

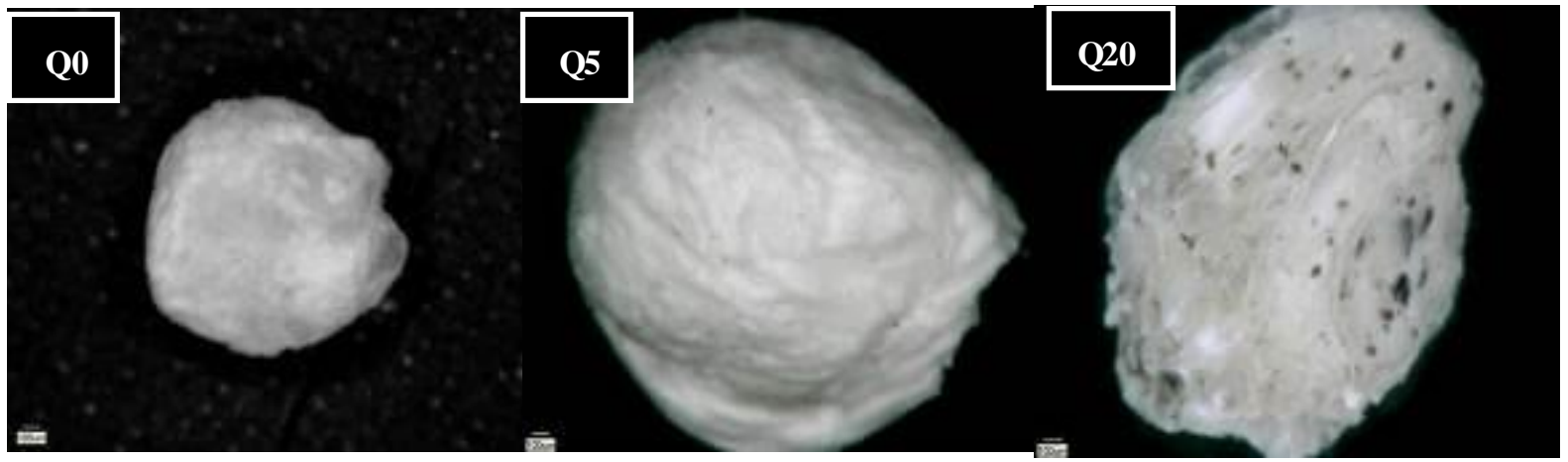

Figura 6: Imagens das esferas no MO com aumento de 100X. (Q0) Esferas de quitosana, (Q5) Esferas quitosana $+5 \%$ EAB e (Q20) Esferas quitosana +20\% EAB (AUTOR, 2017). 


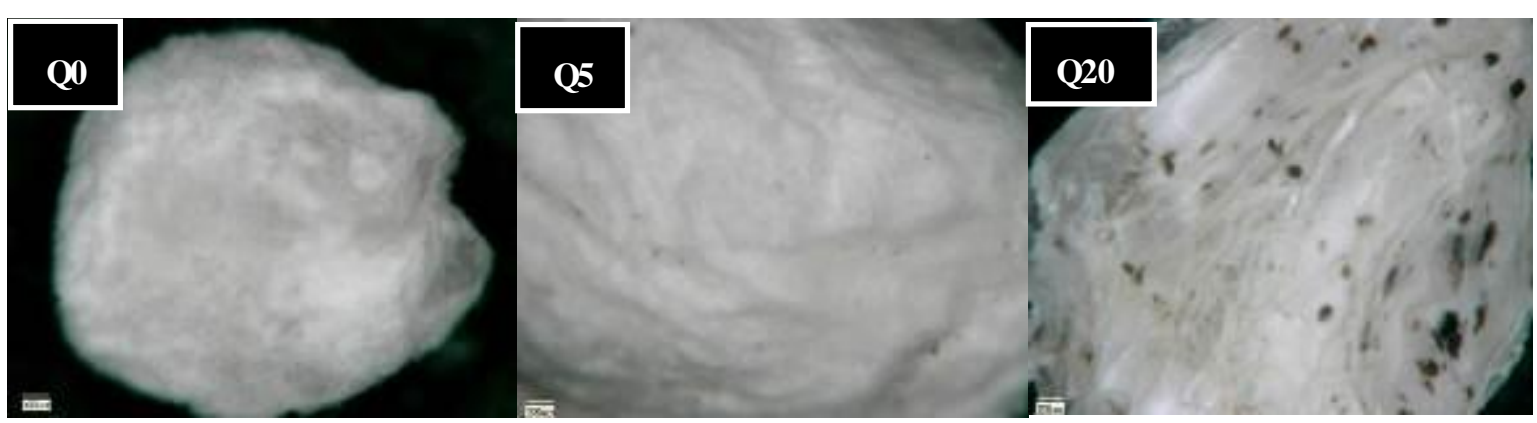

Figura 7: Imagens das esferas no MO com aumento de 160X. (Q0) Esferas de quitosana, (Q5) Esferas quitosana $+5 \%$ EAB e (Q20) Esferas quitosana $+20 \%$ EAB (AUTOR, 2017).

Trabalhando com esferas de quitosana com albumina de soro bovino (BSA), Ma e Liu [17], observaram que a eficiência de encapsulação diminuiu com o aumento da proporção de BSA com relação à quitosana. Sendo a eficiência de encapsulação inferior a $40 \%$ quando a razão em peso de BSA, para quitosana atingiu $20 \%$ com as concentrações de EAB utilizadas no presente trabalho não se observou, por meio do MO, perda na eficiência de encapsulação. O tamanho médio das esferas foram em Q0: 1,8742; Q5: 2,1238 e Q20: 2,2266 micrômetros, já o tamanho médio dos precipitados de EAB não foram mensurados.

De acordo com Bitencourt [18], a incorporação de substâncias ativas pode influenciar a estrutura superficial e interna dos materiais devido a diversos fatores como, tamanho, peso molecular, interações com a matriz polimérica, dentre outros. No caso das esferas de quitosana provavelmente ocorreu uma interação entre o EAB e a quitosana resultando no aumento de tamanho das esferas.

\subsubsection{SUPERFÍCIE INTERNA}

A Figura 8 ilustra a superfície interna das esferas, obtidas por meio do corte das mesmas, utilizando o MO um aumento de 100X e 160X é possível observar que as esferas se tornaram mais escuras à medida que o percentual do extrato de Dysphania ambrosioides (L.) Mosyakin \& Clemants foi aumentado. Destacam-se nessas imagens, aglomerados do EAB de diversos tamanhos que denotam que o mesmo não foi dissolvido de maneira uniforme. As esferas foram se tornando mais escuras, visto que o extrato vegetal apresenta coloração verde bem escuro, denotando a presença do extrato em diferentes concentrações. Porém ele não apresentava solubilidade total na quitosana o que resultou na dispersão não uniforme do mesmo. Tal característica não possui implicação negativa para a aplicação pretendida, visto que por se tratar de um material biodegradável [19], segundo autores, à medida que a rede aumenta de volume, se as redes ou ligações cruzadas são degradáveis, o material começa a dissolver-se e desintegrar-se. Dessa forma toda todo o EAB entrará em contato com o organismo [20]. 


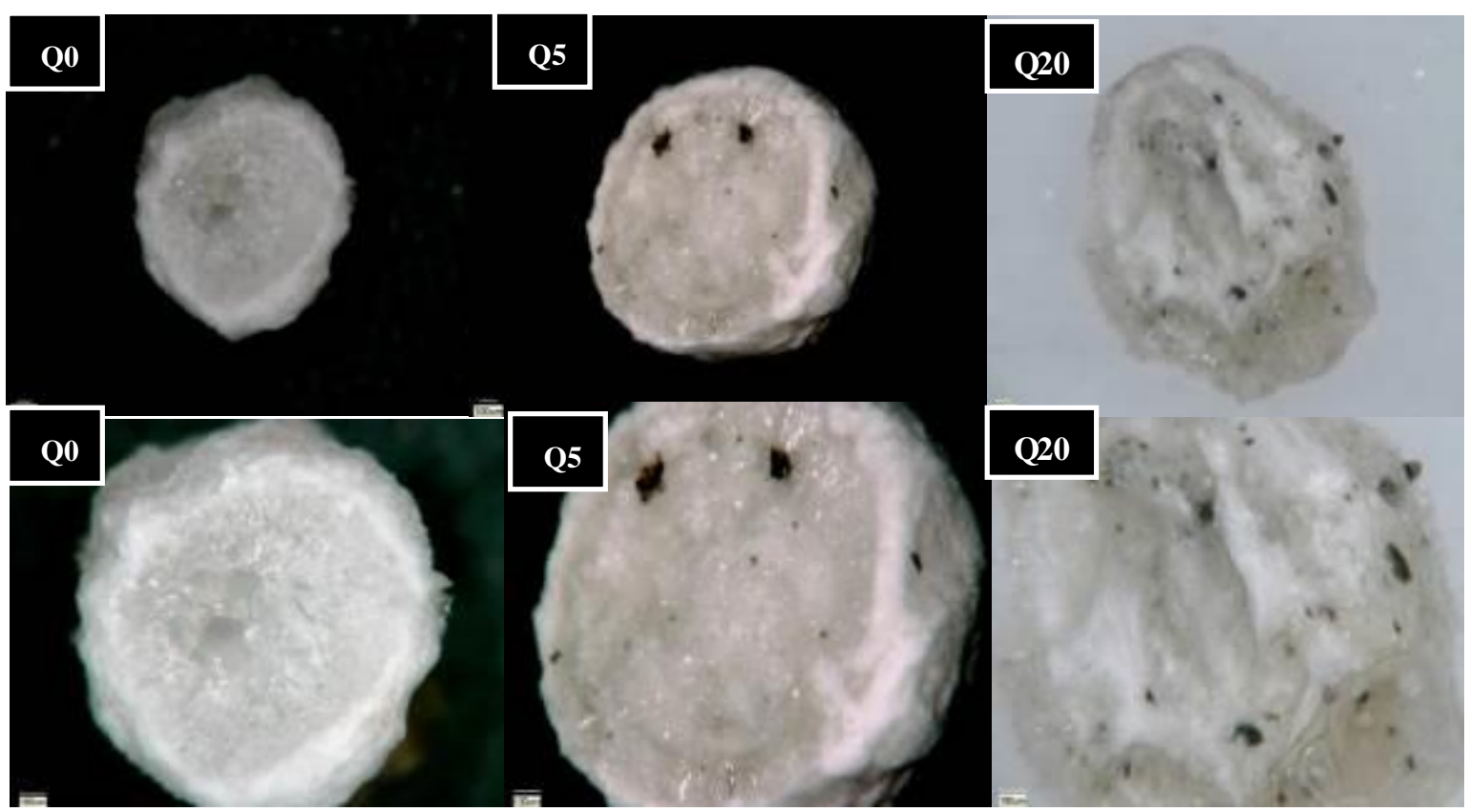

Figura 8: Imagens da superfície interna no MO com aumento de 100X e 160X. (Q0) Esferas de quitosana, (Q5) Esferas quitosana $+5 \%$ EAB e (Q20) Esferas quitosana +20\% EAB (AUTOR, 2017).

\subsection{MICROSCOPIA ELETRÔNICA DE VARREDURA (MEV)}

Foram realizadas imagens da superfície externa das esferas com o MEV utilizando aumentos de 50X, 180X, 1000X e 2000X (Figura 9). As imagens foram obtidas usando feixe de elétrons retro espalhados, com tensão de $15 \mathrm{Kv}$ e uma distância para amostra de aproximadamente $5 \mathrm{~mm}$. 


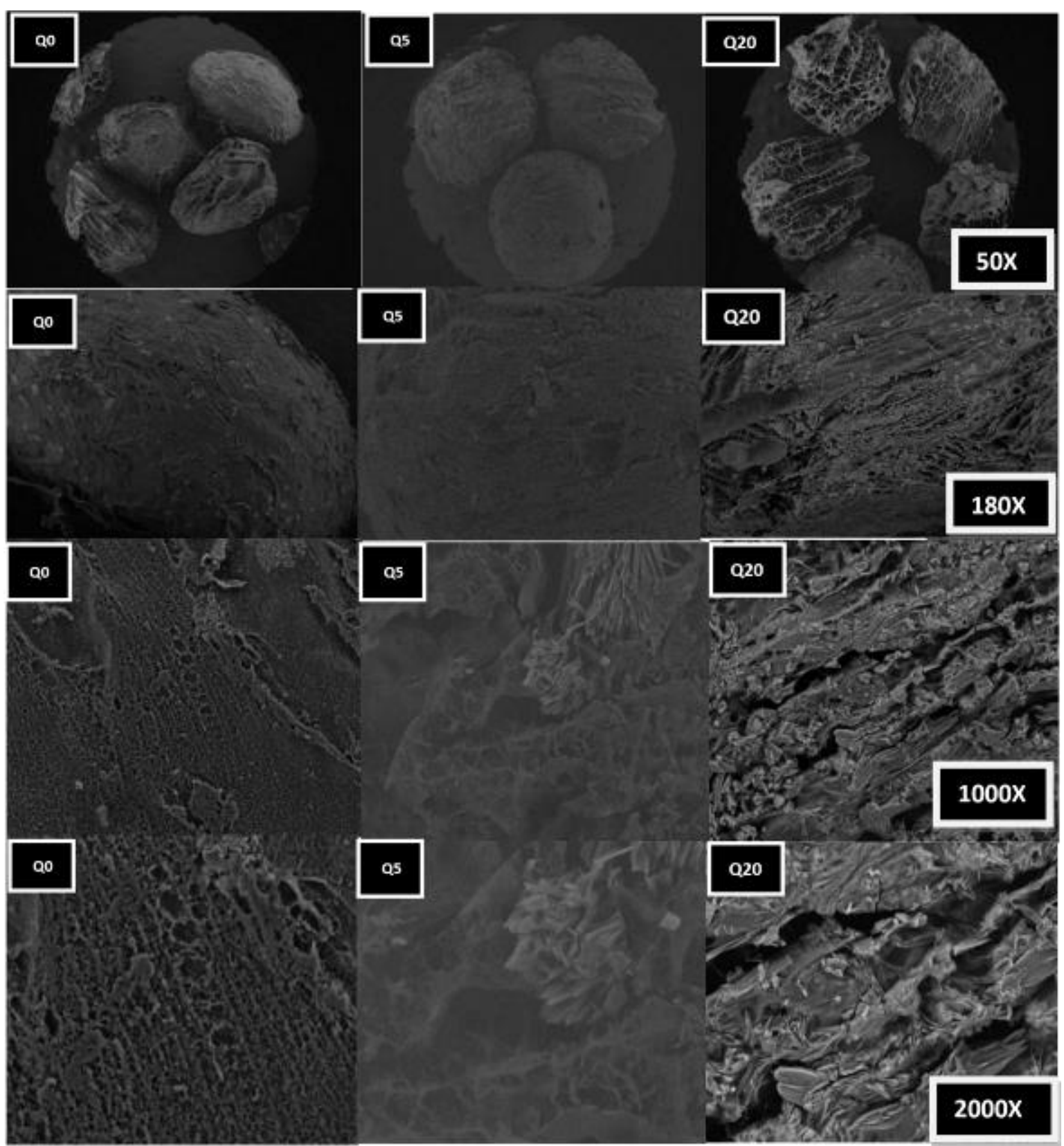

Figura 9: Imagens do MEV com aumento de 50X, 180X,1000X e 2000X. (Q0) Esferas de quitosana, (Q5) Esferas quitosana $+5 \%$ EAB e (Q20) Esferas quitosana +20\% EAB (AUTOR, 2017).

As micrografias denotam que ocorreu uma diminuição do tamanho dos poros na amostra Q5 em relação à Q0, já na amostra Q20 evidenciamos maior quantidade dos poros. O aumento da quantidade de poros gera uma diminuição na densidade das esperas que se dá devido ao processo de liofilização, onde a água presente na quitosana é evaporada, logo, quanto menor o teor de quitosana na esfera, menos água será liberada, menos contração ocorrerá e maior será o tamanho da partícula [21], ao contrário das esferas levadas à estufa onde se tratam de um material denso, sem a presença de poros, decorrente desse processo de secagem que tem como intuito retirar a umidade e também diminuir o tamanho das esferas [22].

Alguns autores observaram a presença de poros intercomunicantes em estruturas tridimensionais de quitosana, em casos que foram realizados o processo de congelamento e liofilização [23, 24, 25], sendo assim, com o intuito de observar se havia presença de poros nas esferas produzidas no atual trabalho proce- 
deu-se a metodologia de congelamento e liofilização das amostras em substituição à secagem na estufa, onde é possível observar esse aumento de intercomunicação dos poros à medida que se adicionou o EAB.

Uma explicação para o surgimento dos poros é o congelamento da água presente em cada esfera, ocorrendo difusão de moléculas de água e agregação em cristais que depois de sublimados na liofilização deixam o espaço vazio observado como poro [26].

Nas amostras, podemos observar algumas variações com relação às características físicas dos poros presentes nas esferas: em Q0 os poros são grandes, em forma de lamelas e o material tem formato ovalado. Já na amostra Q5 observa-se que o material apresenta mais esférico e denso com diminuição no tamanho dos poros. Na amostra Q20 observa-se uma forma esférica, com muitos poros de menor tamanho, quando comparado a Q0, esses poros são uniformes e retangulares com aspecto célula vegetal circundada pela parede celular.

O tamanho e a forma do poro afetam a capacidade de fixação e de crescimento das células e, portanto, influencia a regeneração de tecidos em biomateriais com finalidade osteocondutora, Cheung [27] explicita que esse tamanho e geometria para serem ideais vão depender dos tipos específicos de células cultivadas em locais lesionados, para a osteocondução, o tamanho ideal do poro está na faixa de 75-250 $\mu \mathrm{m}$, além disso propriedades osteoindutoras, como consequência da biodegradação dos seus componentes que é acelerada com a presença dos poros [22, 27].

\subsection{Grau de intumescimento}

$\mathrm{Na}$ quitosana, há predominância dos grupos amino caracterizados por ligações covalentes $(\mathrm{N}-\mathrm{H})$, onde a eletronegatividade das ligações gera sítios de alta polaridade, tornando, assim, favorável o rearranjo das moléculas e água em torno desses sítios. Essa característica estrutural, associada aos grupos acetamidos, caracterizam um material com alto grau de afinidade e retenção de água [28]. A determinação do grau de intumescimento das microesferas é um fator importante, pois pode ajudar a entender o mecanismo de liberação dos ingredientes ativos, a absorção de fluidos corpóreos e a transferência de nutrientes e metabólitos [26].

Para obtenção do GI das esferas de Quitosana e Quitosana/Dysphania ambrosioides (L.) Mosyakin \& Clemants (mastruz) foi realizado o cálculo do intumescimento de acordo com a fórmula (intumescimento final- intumescimento inicial/ intumescimento inicial x100) para todas as amostras, em seguida foi realizada a análise da normalidade pelo teste Shapiro-wilk e a comparação das médias através da ANOVA com nível de significância de $95 \%$, com valor p do teste de 0,1945. Sendo assim na análise das amostras esferas Q0 obteve média de 342,1053\%, Q5 de 278,0488\% e Q20 de 254,902\% (Tabela 1), não havendo diferenças significativas no grau de intumescimento entre os grupos Q0, Q5 e Q20 (Figura 10).

Tabela 1: Cálculos individuais de cada esfera da amostra e médias obtidas após análises (Q0S- esferas de quitosana secas; Q0I- esferas de quitosana intumescidas; Q5S e Q20S esferas de quitosana com 5\% e 20\% de EAB secas; Q5I e Q20I esferas de quitosana com 5\% e 20\% de EAB intumescidas) (AUTOR, 2017).

\begin{tabular}{l|l|l|l|l|l|l|l|l}
\hline QOS & Q01 & Intumescimento & Q5S & Q5I & Intumescimento & Q20S & Q20I & Intumescimento \\
\hline 0,0008 & 0,0044 & $450 \%$ & 0,0007 & 0,0033 & $371,4286 \%$ & 0,001 & 0,0032 & $220 \%$ \\
\hline 0,0007 & 0,0036 & $414 \%$ & 0,0007 & 0,0032 & $357,1479 \%$ & 0,001 & 0,0029 & $190 \%$ \\
\hline 0,0007 & 0,0024 & $242,8571 \%$ & 0,0008 & 0,0026 & $225 \%$ & 0,001 & 0,0039 & $290 \%$ \\
\hline 0,0008 & 0,0032 & $287,5 \%$ & 0,0009 & 0,0032 & $255,5556 \%$ & 0,0011 & 0,004 & $263,6364 \%$ \\
\hline 0,0008 & 0,0033 & $312,5 \%$ & 0,001 & 0,0032 & $220 \%$ & 0,001 & 0,0041 & $310 \%$ \\
\hline 0,00076 & 0,00336 & $342,1053 \%$ & 0,00082 & 0,0031 & $278,0488 \%$ & 0,00102 & 0,00362 & $254,902 \%$ \\
\hline
\end{tabular}




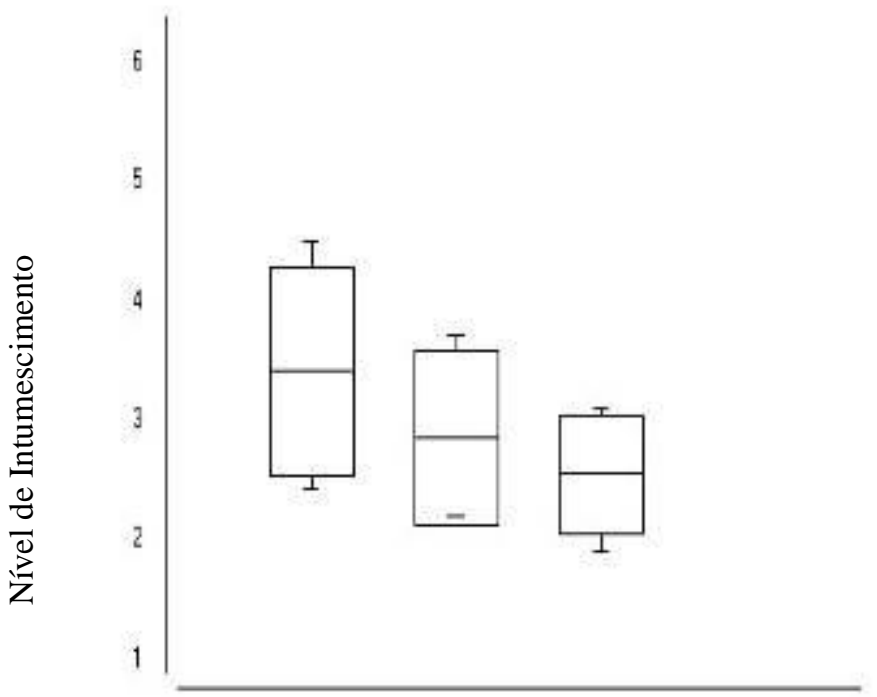

Grupos (Q0, Q5 e Q20)

Figura 10: Gráfico mostrando o nível de intumescimento dos grupos Q0, Q5 e Q20. (AUTOR, 2017).

Tal análise mostra que a adição do EAB não influenciou no grau de intumescimento da quitosana, que, segundo Muzzarelli et al. [29] se destaca por absorver grande quantidade de água, o que resulta em acentuados intumescimento e aumento de volume. $\mathrm{O}$ intumescimento provoca o aumento da porosidade e, portanto, leva à liberação do fármaco.

Não se observou diferença significante quanto ao grau de intumescimento, provavelmente por se tratar de biomateriais degradáveis. De acordo com Hoffman et al. [20], quando um material começa a absorver água, primeiro ocorre a hidratação dos grupos hidrofílicos mais polares e posteriormente dos grupos hidrofóbicos, que também interagem com as moléculas de água. Resultando na absorção de água adicional, devido à força motriz osmótica das cadeias da rede. Assim, o material atinge um nível de equilíbrio de intumescimento.

$\mathrm{O}$ intumescimento da água adicional que é absorvido pelos grupos iônicos, polares e hidrofóbicos tornamse saturados de água, preenchendo o espaço entre as redes e/ou macroporos. À medida que a rede aumenta de volume, se as redes ou ligações cruzadas são degradáveis, o material começa a dissolver-se e desintegrar-se. Esta absorção provavelmente ocorre devido a presença de poros nas esferas, conforme visto por MEV.

A capacidade de intumescimento é muito importante para a absorção de fluidos do corpo e para transferência de nutrientes celulares. $\mathrm{O}$ intumescimento facilita a infiltração das células para os suportes tridimensionais além de aumentar o tamanho dos poros e a porosidade total [30]. Esta é uma propriedade desejada para um biomaterial a ser utilizado na regeneração óssea.

\section{CONCLUSÕES}

Conclui-se que foi possível o desenvolvimento de esferas quitosana/ Dysphania ambrosioides (L.) Mosyakin \& Clemants (mastruz), que no grupo com maior percentual de EAB as amostras apresentaram-se mais escuras e com maior quantidade e intercomunicação dos poros e que, embora tenha havido o intumescimento, não foi observada diferença significativa entre os grupos após o aumento da quantidade de EAB.

\section{AGRADECIMENTOS}

O presente trabalho foi realizado com apoio do CNPq, Conselho Nacional de Desenvolvimento Científico e Tecnológico - Brasil. Ao PIBIC/CNPq-UFCG pela oportunidade dada para o desenvolvimento do projeto.

\section{BIBLIOGRAFIA}

[1] MORAES, A. M.; PIRES, A. L. R.; BIERHALZ A. C. K., Biomateriais: tipos, aplicações e mercado, Quim. Nova, v. 38, n. 7, pp. 957-971, 2015. 
[2] PINHEIRO, T. C. et al. Implantes de hidroxiapatita em falhas reduzidas no fêmur em ratos submetidos ao tabagismo passivo. Revista Brasileira de Ortopedia, v. 43, pp. 433-441, 2008.

[3] COSTA, B. D. et al. Neoformação e acesso a osteointegração de biomateriais micro e nanoestruturados em ovinos. Pesquisa Veterinária Brasileira, v. 35, pp. 177-187, 2015.

[4] WAN, D.C.; NACAMULI, R.P.; LONGAKER, M.T. Craniofacial Bone Tissue Engineering. Dent. Clin. N. Am., v.50, n.2, pp.175-190, 2006.

[5] CHEN, K-Y. et al. Reconstruction of calvarial defect using a tricalcium phosphate-oligomeric proanthocyanidins cross-linked gelatin composite. Biomaterials, v.30, n.9, pp.1682-1688, 2009.

[6] OLIVEIRA, L.S.; OLIVEIRA, C. S.; MACHADO, A. P. L.; ROSA, F. P. Biomateriais com aplicação na regeneração óssea - método de análise e perspectivas futuras. Revista de Ciências Médicas e Biológicas, v.9, s. 1, pp.37-44, 2010.

[7] TAVARIA, F. K.; JORGE, M.; MARCHETTI, G.; et al. Wound healing, anti-ulcerogenic, antiinflammatory and anti-proliferative properties of chitosan. New Biotechnology. 2009; disponível em: <http://dx.doi. org/10.1016/j.nbt.2009.06.027>. Acesso em 10 de fev. de 2017

[8] MINAGAWA, T.; OKAMURA, Y.; SHIGEMASA, Y.; et al. Effects of molecular weight and deacetylation degree of chitin/chitosan on wound healing. Carbohydrate Polymers, 2007; disponível em: < http://dx.doi.org/10.1016/j. carbpol.2006.07.007>. Acesso em 10 de fev. De 2017

[9] TAVARIA, F. K.; COSTA E.M.; PINA-VAZ, I.; et al. Quitosana como biomaterial odontológico: estado da arte. Revista Brasileria de engenharia Biomédica, v.29, n. 1, pp. 110-120, 2013.

[10] LAPA, A. J.; SOUCCAR, C.; LIMA-LANDMAN, M. T. R.; GODINHO, R. O.; NOGUEIRA, T. C. M. L. 2003. Farmacologia e toxicologia de produtos naturais. In: SIMÕES, C. M. O.; SHENKEL, E. P.; GOSMANN, G.; MELLO, J. C. P.; MENTZ, L. A.; PETROVICK, P.R. (org.) Farmacognosia: da Planta ao medicamento.5.ed. Porto Alegre/Florianópolis: Editora da UFRGS/Editora da FSC, pp.247-262, 2007.

[11] SOUSA, J. A.; MIRANDA, E. M. Plantas medicinais e fitoterápicos: alternativas viáveis. Acre, 18 dez. 2003. Disponível em: <http://www.cpafac.embrapa.br >. Acesso em 28 jan. 2015.

[12] PENHA ES, LACERDA SR, CARVALHO MGF, OLIVEIRA PT. Effect of Chenopodium ambrosioides on the healing process of the in vivo bone tissue. Microsc Res Tech. https://doi.org/10.1002/jemt.22913, n. 00 , pp. 1-7, 2017.

[13] SOUSA, J. N. L. Ação da aroeira (schinus terebinthifolius raddi) e do mastruz (chenopodium ambrosioides l) no processo de reparo de dentes de ratos reimplantados. Dissertação (Mestrado em Odontologia). Universidade Potiguar. Natal, 131f., 2010.

[14] SERVIO, E. M. L., ARAUJO, K. S., NASCIMENTO, L. R. S., Costa, C. L. S., MENDES, L. M. S., \& FILHO, A. L. M. M. Wound healing using Chenopodium ambrosioides (mastruz) extract and sterile secondary coverage in rats. ConScientiae S, n. 10, pp.441-448, 2011

[15] MARINS, A. K.; VIEIRA, D. F.; QUADROS, I. P. S.; PINHEIRO, P. F.; QUEIROZ, V. T.; COSTA, A. V. Prospecção fitoquímica das partes aéreas da Erva-de-Santa-Maria (Chenopodium ambrosioides L.). In: Encontro Latino Americano de Iniciação Científica e Encontro Latino Americano de Pós-Graduação, Alegre, Espírito Santo, v. 15, pp.1-5, 2011.

[16] BRASILEIRO, B. G.; PIZZIOLO, V. R.; RASLAN, D. S.; et al. Antimicrobial and cytotoxic activities screen in some Brazilian medicinal plants used in Governador Valadares district. Revista Brasileira de Ciências Farmacêuticas, v. 42, n. 2, p. 195-202, 2006.

[17] MA. L.; LIU, C. Colloids and Surfaces: Biointerfaces, v.75, n.448, 2010.

[18] BITENCOURT, C.M. Desenvolvimento e aplicação de filmes á base de gelatina aditivados com extrato etanólico de cúrcuma (Curcuma longa L.). Dissertação (Mestrado em Ciência da Engenharia de Alimentos). Faculdade de Zootecnia e Engenharia de Alimentos, Universidade de São Paulo, Pirassununga - São Paulo, 107f, 2013.

[19] MEDEIROS, L.; BARBOSA, R.; ROSENDO, R.; et al. Esferas de quitosana/D. ambrosioides (mastruz) para aplicação como biomaterial. Rev. bras. odontol., Rio de Janeiro, v. 73, n. 2, pp. 124-9, abr./jun. 2016 [20] HOFFMAN, S.A.; Hydrogels for biomedical applications. Advanced Drug Delivery Reviews, Seatle, v. 64, pp. 18-23, 2012.

[21] DANTAS, L. M.; FIDÉLIS, T.; CARRODEGUAS, R.; et al. Obtenção e caracterização de esferas de quitosana/hidroxiapatita gerada in situ. Revista Eletrônica de Materiais e Processos, América do Sul, v.11, pp.20, 2017.

[22] MEDEIROS, L.A.D.M.; Desenvolvimento de esferas de quitosana/ dysphania ambrosioides(L.) Mosyakin \& clemants para aplicação como biomaterial. Tese (Doutorado em Ciência e Engenharia de Materiais). Centro de Ciência e Tecnologia. Universidade Federal de Campina Grande, Campina Grande, 2016. [23] FÁVERE, V. T.; LARANJEIRA, M. C. M. Quitosana: Biopolímero Funcional com Potencial Industrial Biomédico. Quim. Nova, v. 32, n. 3, pp. 672-678, 2009. 
[24] FOOK, A. C. B. M. Produção e caracterização de arcabouços compósitos HA/Biopolímero para engenharia de tecidos. Tese (Doutorado em Ciência e Engenharia de Materiais). Centro de Ciência e Tecnologia. Universidade Federal de Campina Grande, Campina Grande, 2012.

[25] CRUZ, J. B. Arcabouços de quitosana/agente antineoplásico: síntese, caracterização e aplicação. Tese (Doutorado em Ciência e Engenharia de Materiais). Centro de Ciência e Tecnologia. Universidade Federal de Campina Grande, Campina Grande, 118f, 2015.

[26] W, T.-H. W.; YINDEE, K. Chitosan scaffolds for in vitro buffalo embryonic stem-like cell culture: An approach to tissue engineering. Journal of Biomedical Materials Research Part B: Applied Biomaterials, v. 80B, n. 1, pp. 92-101, 2006.

[27] CHEUNG, H. Y.; LAU, K. T.; LU, T. P.; HUI D. A critical review on polymer-based bio-engineered materials for scaffold development. Composites Part B: Engineering, v. 38, n. 3, pp. 291-300, 2007.

[28] ASSIS, O.B.G. et al; "Caracterização estrutural e da capacidade de absorção de água em filmes finos de quitosana processados em diversas concentrações”. Polímeros: Ciência e Tecnologia, v.13, n 4, pp. 223228.

[29] MUZZARELI, R. A. A.; MATTIOLI-BELMONTE, M.; TIETZ, C.; et al. Stimulatory effect on bone formation exerted by a modified chitosan. Biomaterials, Disponível em: <http://link.periodicos.capes.gov.br.ez15., v.15. pp.1075-1081,1994.

[30] OLAD, A.; AZHAR, F. F. The synergetic effect of bioactive ceramic and nanoclay on the properties of chitosan-gelatin/nanohydroxyapatite-montmorillonite scaffold for bone tissue engineering. v. 40, n.7, Part A, pp.10061-10072, 2014

\section{ORCID}

Ana Beatriz Maximo Figueiredo

Arthur Willian de Lima Brasil

Luanna Abílio Diniz Melquíades de Medeiros

Marcus Vinícius Lia Fook

Mylena de Araújo Régis

Rafael Rodrigues de Siqueira

Rossemberg Cardoso Barbosa

Rosana Araújo Rosendo

Walter Gleybson Antas de Moraes

https://orcid.org/0000-0002-3198-8993

https://orcid.org/0000-0002-1862-6517

https://orcid.org/0000-0002-1630-3968

https://orcid.org/0000-0002-8566-920x

https://orcid.org/0000-0003-1673-0414

https://orcid.org/0000-0002-0748-3506

https://orcid.org/0000-0002-8551-5251

https://orcid.org/0000-0002-3795-8832

https://orcid.org/0000-0002-2128-5573 